\title{
Ethanol Self-Administration Restores Withdrawal-Associated Deficiencies in Accumbal Dopamine and 5-Hydroxytryptamine Release in Dependent Rats
}

\author{
Friedbert Weiss, Loren H. Parsons, Gery Schulteis, Petri Hyytiä, Marge T. Lorang, Floyd E. Bloom, and \\ George F. Koob
}

Department of Neuropharmacology, The Scripps Research Institute, La Jolla, California 92037

\begin{abstract}
Basal forebrain dopamine (DA) and 5-HT neurotransmission has been implicated in the mediation of the acute reinforcing actions of ethanol. Neuroadaptation theories predict that compensatory changes in neurochemical systems that are activated by alcohol acutely may underlie symptoms of withdrawal after chronic administration. To test this hypothesis, the release of DA and 5-HT was monitored by microdialysis in the nucleus accumbens of dependent male Wistar rats at the end of a 3-5 week ethanol $(8.7 \% \mathrm{w} / \mathrm{v})$ liquid diet regimen, during $8 \mathrm{hr}$ of withdrawal, and during renewed availability of ethanol involving (1) the opportunity to operantly self-administer ethanol $(10 \%$ $\mathrm{w} / \mathrm{v}$ ) for $60 \mathrm{~min}$, followed by (2) unlimited access to the ethanolliquid diet. Results were compared to control groups pair-fed with ethanol-free liquid diet and trained to self-administer either ethanol or water. In nondependent rats, operant ethanol self-
\end{abstract}

administration increased both DA and 5-HT release in the NAC. Withdrawal from the chronic ethanol diet produced a progressive suppression in the release of these transmitters over the 8 $\mathrm{hr}$ withdrawal period. Self-administration of ethanol reinstated and maintained DA release at prewithdrawal levels but failed to completely restore 5-HT efflux. 5-HT levels recovered rapidly, however, within $1 \mathrm{hr}$ of reexposure to ethanol liquid diet. These findings suggest that deficits in accumbal monoamine release may contribute to the negative affective consequences ethanol withdrawal and, thereby, motivate ethanol-seeking behavior in dependent subjects.

Key words: ethanol; dopamine; 5-HT; microdialysis; nucleus accumbens; self-administration; dependence; withdrawal; reinforcement
Alcohol abuse and dependence with their medical and social pathologies remain among the greatest substance abuse problems in the U.S. and worldwide (Nelson and Stussman, 1994; Greenfield and Weisner, 1995; Rice and Harris, 1995). Alcohol has anxiolytic and euphorigenic actions, and these properties are thought to contributc to the acutc reinforcing effects of alcohol that can lead to continued use and ultimately severe abuse and dependence in susceptible individuals. Significant progress has been made in recent years with regard to the identification of neurotransmitter and receptor systems that participate in the mediation of ethanol's acute reinforcing effects (for review, see Gianoulakis, 1989; Hoffman et al., 1990; Samson, 1992; Sellers et al., 1992; Froehlich and Li, 1993; Hunt, 1993; Grant, 1994; Tabakoff and Hoffman, 1996; Mihic and Harris, 1995).

Among the numerous neurotransmitter systems implicated in the pharmacological effects of alcohol, dopamine (DA) and 5-HT have received particular attention because of their putative role in the motivational effects of ethanol (Cloninger, 1987; McBride et al., 1991; Engel et al., 1992; Samson, 1992; Sellers et al., 1992). In the case of DA, compelling electrophysiological (Gessa et al,,

Received Nov. 2, 1995; revised Feb. 23, 1996; acceptcd Fcb. 28, 1996.

This work was supported by National Institute on Alcohol Abuse and Alcoholism Grants $\Lambda \Lambda 08164$ and $\mathrm{A} \Lambda 10531$ (F.W.) and by National Institute on Alcohol Abuse and Alcoholism Specialized Center Grant AA 06420 (G.K., F.W.; Director, G.F.K.). P.H. was a visiting scientist from the Biomedical Research Center, Alko Ltd., Helsinki, Finland. This is publication number NP-8871 from The Scripps Research Institute.

Correspondence should be addressed to Friedbert Weiss, Department of Neuropharmacology (CVN-15), The Scripps Research Institute, 10666 North Torrey Pines Road, La Jolla, CA 92037.

Copyright (C) 1996 Society for Neuroscience $0270-6474 / 96 / 163474-12 \$ 05.00 / 0$
1985; Brodie et al., 1990), neurochemical (Imperato and DiChiara, 1986; Wozniak et al., 1991; Yoshimoto et al., 1991; Engel et al., 1992), and behavioral (Imperato and DiChiara, 1986; Waller et al., 1986) evidence indicates that behaviorally relevant doses of ethanol activate the mesolimbic DA reward pathway. Direct evidence of a role for DA in ethanol reward comes from findings that operantly self-administered ethanol stimulates DA release in the NAC (Weiss et al., 1993), that rats will self-administer ethanol directly into the ventral tegmental cell body region of the mesoaccumbens DA reward pathway (Gatto ct al., 1994), and that operant responding for ethanol is modified by pharmacological agents that interact with DA neurotransmission (McBride et al., 1990; Samson et al., 1991; Hodge et al., 1993; Rassnick et al., 1993). Finally, alcohol preference in genetic models of alcoholism has been linked to reduced DA content in the NAC (Murphy et al., 1982; Murphy et al., 1987; Gongwer et al., 1989) as well as heightened sensitivity to the DA release-enhancing and locomotor activating effects of ethanol (Waller et al., 1986; Cloninger, 1987; Fadda et al., 1989; Engel et al., 1992; Weiss et al., 1993).

Ample evidence exists for an involvement of 5-HT in ethanolseeking behavior as well. Ethanol dose-dependently increases 5-HT release in the NAC (Yoshimoto et al., 1992), whereas pharmacological treatments that increase the synaptic availability of 5-HT, or direct activation of 5-HT transmission by receptor agonists suppress voluntary ethanol intake in animals (for review, see Sellers et al., 1992; LeMarquand et al., 1994) and can reduce alcohol consumption in humans (Naranjo et al., 1984, 1987, 1989, 1990; Gorelick, 1989; Monti and Alterwain, 1991). A serotonergic role in ethanol abuse is supported also by findings of marked deficiencies in forebrain 5-HT content, reduced 5-HT innervation, 
or upregulation of 5-HT1A receptors in genetically selected, alcohol-preferring rodent lines (Murphy et al., 1982, 1987; Yoshimoto et al., 1985; Yoshimoto and Komura, 1987; Gongwer et al., 1989; McBride et al., 1990, 1994). Finally, the subjective effects of ethanol depend, at least partially, on 5-HT neurotransmission since agonists of the 5-HT1A receptor substitute for (Signs and Schechter, 1988; Grant and Colombo, 1993; Krystal et al., 1994), whereas 5-HT3 antagonists block the discriminative stimulus properties of ethanol (Grant and Barrett, 1991).

To date, the great majority of studies on the neuropharmacological basis of ethanol-maintained reinforcement have been conducted in nondependent animals. However, understanding of the mechanisms maintaining ethanol abuse also requires insight into the biological basis of ethanol-maintained reinforcement in dependent subjects. It has been suggested that the development of dependence involves adaptations at the cellular or molecular level that oppose the pharmacological actions of substances of abuse and, thereby, lead to the emergence of withdrawal symptoms that could motivate continued consumption of the drug (Koob and Bloom, 1988). In view of previous evidence that ethanol stimulates the release of both DA and 5-HT in the NAC (Imperato and DiChiara, 1986; Wozniak et al., 1991; Yoshimoto et al., 1992; Weiss et al., 1993), this hypothesis would predict a deficiency in the release of these neurotransmitters during ethanol withdrawal. By extension, this hypothesis would also predict a reversal of withdrawal-induced neurochemical deficiencies after renewed exposure to ethanol. To test this hypothesis, the present experiments examined the effects of chronic ethanol exposure and ethanol withdrawal on the release of DA and 5-HT in the NAC using intracerebral microdialysis, as well as the role of accumbal monoamine release in ethanol-maintained reinforcement in dependent rats.

\section{MATERIALS AND METHODS}

\section{Subjects}

Male Wistar rats (Charles River) weighing between $400-600 \mathrm{gm}$ at the time of testing were used. The rats were housed in groups of two or three in a humidity and temperature $\left(22^{\circ} \mathrm{C}\right)$ controlled vivarium on a $12 / 12 \mathrm{hr}$ light/dark cycle (on 05:00, off 17:00) with ad libitum access to food and water. All procedures were conducted in strict adherence to the National Institutes of Health Guide for the Care and Use of Laboratory Animals.

\section{Behavioral testing apparatus}

Ethanol self-administration training and microdialysis testing was conducted in standard operant chambers (Coulbourn Instruments, Allentown, PA) modified as described previously (Weiss et al., 1993) to permit concurrent presentation of two different liquid reinforcers and to accommodate components of the microdialysis perfusion system. Briefly, the operant chambers were equipped with two retractable levers. Responses at the appropriate operandum resulted in presentation of either $0.1 \mathrm{ml}$ ethanol solution or water into one of two receptacles (volume capacity $0.15 \mathrm{ml}$ ) positioned $4 \mathrm{~cm}$ above the grid floor and between the levers in the center of the front plate of the operant chamber. The operant chambers were located in a laboratory procedure room attached to the vivarium and were enclosed in sound-attenuated, ventilated environmental cubicles (Coulbourn Instruments, Allentown, PA). Fluid delivery and behavioral recording was controlled by microcomputer.

\section{Ethanol self-administration training}

Rats were trained to self-administer ethanol or water p.o. in a two-lever, free-choice operant task using a modified (Weiss and Koob, 1991) sweetsolution fading procedure (Samson, 1986). Rats were initially placed on a $22 \mathrm{hr}$ water deprivation schedule (limited to two consecutive days) and trained in daily $30 \mathrm{~min}$ sessions to respond on either of two levers for a $0.2 \%(\mathrm{w} / \mathrm{v})$ saccharin solution on a schedule of continuous reinforcement. After successful acquisition of operant responding, water was made available again ad libitum in the home cage. For the next $6 \mathrm{~d}$, responding at a single available lever resulted in delivery of a $0.1 \mathrm{ml}$ ethanol $(5 \%) /$ saccharin $(0.2 \%)$ solution. The animals were then trained on a concurrent schedule in which each press at one lever resulted in delivery of the ethanol/saccharin solution whereas responses at the other lever resulted in presentation of water at an equal volume $(0.1 \mathrm{ml})$. During subsequent training ethanol concentrations were gradually raised to $10 \%$ (w/v) while the concentration of saccharin was slowly decreased, followed by complete elimination of the sweetener from the drinking solution. After completion of this sweet-solution fading stage that lasted $19 \mathrm{~d}$, self-administration sessions were continued for another $16-21 \mathrm{~d}$ until stable levels of ethanol $(10 \% \mathrm{w} / \mathrm{v})$ intake were observed. All free-choice training and testing was conducted without food or fluid restrictions.

To control for the effects of simple exposure to the operant box on neurotransmitter release, ethanol-naive rats habituated to the test environment were also prepared. To provide operant histories comparable to those of ethanol self-administering rats, these control animals were initially also placed on a $22 \mathrm{hr}$ fluid restriction schedule (limited to two consecutive days), but were trained to lever-press for water only. After acquisition of operant responding, water was made available again ad libitum in the home cage, but the rats continued to receive daily $30 \mathrm{~min}$ access to water in the self-administration chambers. Consistent with previous results (Weiss et al., 1993), these animals ceased responding for water at appreciable rates without further deprivation, thus providing a suitable "nonmotivated" control group.

\section{Stereotaxic surgery}

Once stable levels of ethanol self-administration were obtained, the rats were stereotaxically implanted for awake microdialysis with a chronic indwelling stainless steel guide cannula aimed at the NAC under halothane $(1.0-1.5 \%)$ anesthesia. The guide cannulae (C313CS, Plastics One, Roanoke, VA) were lowered unilaterally to $2.0 \mathrm{~mm}$ above the dorsal border of the dialysis site and secured with stainless steel skull screws and dental cement. With reference to bregma, the coordinates were anterior +1.3 , medial \pm 1.6 , and ventral -4.2 according to the atlas of (Paxinos and Watson, 1986). Using microdialysis probes with $2.0 \mathrm{~mm}$ active membrane tips (protruding beyond the guide cannula), the dialysis sites were located between ventral coordinates -6.2 and -8.2 .

\section{Induction of ethanol dependence: liquid diets}

Beginning $4 \mathrm{~d}$ after surgery, recovery of responding for ethanol was verified by resuming daily $30 \mathrm{~min}$ ethanol self-administration sessions. When stable levels of intake were again observed rats were made dependent on ethanol using the liquid diet method (Lochry and Riley, 1980). Details of the liquid diet procedure adapted in this laboratory have been reported previously (Rassnick et al., 1992). Briefly, the ethanol diet was prepared fresh daily (9:00 to 10:00 A.M.) by supplementing chocolateflavored Sustacal, a nutritionally complete liquid food (Mead Johnson, Inc.) with ethanol $(95 \% \mathrm{w} / \mathrm{v})$, a vitamin/mineral mixture (ICN Nutritional Biochemicals), and water to create an ethanol-containing liquid diet $(8.7 \% \mathrm{w} / \mathrm{v})$ which provides approximately $35 \%$ ethanol-derived calories (Lochry and Riley, 1980). This procedure has typically produced blood ethanol concentrations (BACs) ranging from 80 to $180 \mathrm{mg} \%$ in similar, previous work in our laboratory (Merlo Pich et al., 1995; Schulteis et al., 1996). Control rats received an equicaloric non ethanol-containing diet containing sucrose. To keep caloric intake and body weights in rats maintained on control diet equal to that of ethanol-exposed rats, a pair-feeding procedure was used whereby animals receiving ethanol diet were given unlimited access, whereas control diet was given in restricted amounts each day (for details, see Schulteis et al., 1996).

\section{Intracranial microdialysis}

Perfusion system. A previously described perfusion system (Weiss et al., 1993) modified to accommodate the methods of Parsons and Justice (1992) was used. Briefly, dialysis inlet and outlet tubing consisted of fused silica (40 $\mu \mathrm{m}$ i.d.) and was protected inside the flexible spring cover of a cannula connector (C313CS, Plastics One, Roanoke, VA). The dialysis inlet tubing was passed from the perfusion pump to the microdialysis probe via a two-channel liquid swivel (Instech, Plymouth Meeting, PA) positioned above the center of the cage by means of a balancing lever. The inlet tubing was connected via the liquid swivel to a $1 \mathrm{ml}$ Hamilton syringe containing artificial CSF (aCSF) as perfusion medium. The perfusion medium was delivered by a pulseless syringe pump (CMA/100; Bioanalytical Systems, West Lafayette, IN). Dialysate was collected manually into $250 \mu \mathrm{l}$ microfraction vials. Samples were immediately frozen on dry ice and stored at $-70^{\circ} \mathrm{C}$ until assayed. 
Materials and general procedures. Intracerebral guide cannulae and concentric microdialysis probes (outer diameter: $300 \mu \mathrm{m}$; membrane material, regenerated cellulose; length, $2 \mathrm{~mm}$ ) were constructed as described by Parsons and Justice (1992). The probes were perfused with $\mathrm{aCSF}$ at a rate of $0.2 \mu \mathrm{l} / \mathrm{min}$ and slowly inserted under brief, shallow halothane anesthesia ( $<5 \mathrm{~min}$ ) $16 \mathrm{hr}$ before the start of testing and dialysate collection. [Five animals were tested with commercially available microdialysis probes (CMA/10; Bioanalytical Systems, West Lafayette, IN) perfused at a flow rate of $0.5 \mu \mathrm{l} / \mathrm{min}$.] To habituate rats to the microdialysis test procedures the animals were connected daily to an inactive perfusion system (without insertion of microdialysis probes) in the home cage for $\sim 2$ weeks before testing.

Perfusion medium. ACSF consisting of $149 \mathrm{mM} \mathrm{NaCl}, 2.8 \mathrm{mM} \mathrm{KCl}, 1.2$ $\mathrm{mm} \mathrm{CaCl} 2,1.2 \mathrm{~mm} \mathrm{MgCl}$, and 5.4 mM D-glucose ( $\mathrm{pH} 7.2-7.4$ ) was used. Ascorbic acid was added as an antioxidant at a concentration $(0.25 \mathrm{~mm})$ similar to that found in striatal extracellular space.

\section{Experimental design and procedures}

Effects of chronic ethanol exposure (DEPENDENT), withdrawal, and subsequent operant self-administration on extracellular levels of DA and 5-HT (as measured by conventional microdialysis) were compared to two control conditions consisting of (1) "ethanol-acclimated" rats with the same history of ethanol self-administration training, but not made dependent on ethanol (NONDEPENDENT), and (2) nonethanol-exposed rats trained to self-administer water only (ETHANOL-NAIVE). To ensure similar distributions of ethanol intake in the two ethanol-exposed experimental groups, only rats with stable rates of ethanol intake $( \pm 10 \%$ over three consecutive days at the end of self-administration training) of at least 0.5 $\mathrm{gm} / \mathrm{kg} / 30 \mathrm{~min}$ session were included in the experiment. Rats meeting this selection criterion were then matched, as much as possible, on the basis of their baseline ethanol intake before their assignment to the NONDEPENDENT and DEPENDENT conditions. The three groups of rats were maintained on the ethanol (DEPENDENT) or control liquid diets (NONDEPENDENT and ETHANOL-NAIVE) as their only source of nutrition and fluids. The duration of exposure to the liquid diets was 3-5 weeks (mean \pm SEM number of days: $26.95 \pm 2.19$ ) for DEPENDENT and NONDEPENDENT rats, and $2-3$ weeks $(16.84 \pm 1.65 \mathrm{~d})$ in the ETHANOL-NAIVE group. During this time no operant self-administration sessions were conducted and rats remained confined to their home cages. Monitoring of extracellular DA and 5-HT concentrations in the NAC by microdialysis was begun in the rats' home cages during the final $2 \mathrm{hr}$ of exposure to the ethanol liquid diet (or the corresponding time period in nondependent and ethanol-naive rats) and continued throughout the subsequent withdrawal and self-administration stages. Ethanol withdrawal was then precipitated by substitution of control liquid diet for ethanol-containing diet $(40 \mathrm{ml})$ for $8 \mathrm{hr}$. To equalize as much as possible the amounts of control diet consumed by the three treatment groups on the test day, NONDEPENDENT and ETHANOL-NAIVE rats were given a restricted amount of diet to parallel the amounts of diet consumed by DEPENDENT rats. Specifically, between the time of insertion of microdialysis probes (on the night before the experiment) and the onset of the "withdrawal" phase, NONDEPENDENT and ETHANOL-NAIVE rats received $70 \mathrm{ml}$ of control diet, corresponding to the average amount of ethanol diet consumed by the DEPENDENT rats. At the beginning of the withdrawal phase, the ETHANOL-NAIVE and NONDEPENDENT groups received an additional $40 \mathrm{ml}$ of control diet corresponding to the amount given to DEPENDENT rats. All rats had consumed most of the control diet by the end of the withdrawal phase, and no differences in the amounts of diet consumed were evident among groups. After $4-6 \mathrm{hr}$ of withdrawal the rats were transferred in their home cages from the vivarium to the laboratory room containing the self-administration stations where thcy remained in their home cages until 8 $\mathrm{hr}$ after ethanol. An $8 \mathrm{hr}$ withdrawal period was chosen because of earlier observations that withdrawal symptoms reach peak between 8 and $12 \mathrm{hr}$ after removal of ethanol diet with this and similar liquid diet methods (Hunter et al., 1974; Rassnick et al., 1992; Schulteis et al., 1996). At this time the animals were placed into the operant chambers and given the opportunity to selfadminister $10 \%(\mathrm{w} / \mathrm{v})$ ethanol (DEPENDENT and NONDEPENDENT) or water (ETHANOL-NAIVE) for $60 \mathrm{~min}$. Thirty minutes after the end of the self-administration session the rats were returned to their home cages where they received unlimited access to their respective diets. The tests were conducted at the same time of day (6:00 A.M. to 10:00 P.M.) in all rats. Throughout the entire experiment dialysate was collected at 20 min intervals except during operant ethanol self-administration when sampling was conducted at $10 \mathrm{~min}$ intervals.

\section{HPLC monoamine assays}

DA and 5-HT dialysate concentrations were determined simultaneously in each sample by microbore reverse-phase HPLC. Dialysate was injected onto a $5 \mu \mathrm{m}$ ODS- 2 column $(0.5 \times 100 \mathrm{~mm}$; packed in house) via a VALCO high pressure valve fitted with a $1.0 \mu \mathrm{l}$ internal sample loop. The mobile phase consisted of a citric acid $(0.02 \mathrm{M}) / \mathrm{sodium}$ phosphate (monobasic, $0.04 \mathrm{M}$ ) buffer containing $0.82 \mathrm{mM} 1$-decanesulfonic acid as an ion-pairing reagent, $4.9 \mathrm{~mm}$ triethylamine, $0.2 \mathrm{mM} \mathrm{Na}{ }_{2}$ EDTA, and $19 \%$ methanol (apparent $\mathrm{pH}$ 5.4). Mobile phase was pumped through the column by an ISCO (model 500) HPLC syringe pump at a rate of 16 $\mu \mathrm{l} / \mathrm{min}$. Analytes were detected electrochemically using an EG\&G Princeton Applied Research [(PARC) model 400] amperometric controller, a glassy carbon working electrode (PARC, model MP 1304), and $\mathrm{Ag} / \mathrm{AgCl}$ reference electrode (BAS, model RE1). The applied potential was $700 \mathrm{mV}$ (vs $\mathrm{Ag} / \mathrm{AgCl}$ ). Detection limits defined by a signal:noise ratio of $>2$ were $0.5 \mathrm{nM}$ for both DA and 5-HT.

\section{Blood alcohol determination}

BACs were measured once in each rat 3-4 d after postexperimental recxposurc to the cthanol dict. BACs were determined after completion of the experiments only because of the possibility of introducing artifacts on neurotransmitter release by blood sampling procedures during microdialysis testing. A sample of $0.1 \mathrm{ml}$ of blood was obtained by the tail bleed method between 12:00 and 2:00 P.M. Blood was collected into sealed Eppendorf vials containing $4 \mu \mathrm{l}$ of heparin (1000 USp units/ml) as an anticoagulant and centrifuged at $3200 \mathrm{rpm}$. The serum was extracted with trichloroacetic acid and assayed for ethanol content using the NADNADH enzyme spectrophotometric method (Sigma, St. Louis, MO).

\section{Histology}

Microdialysis sites were histologically examined after completion of the experiments. Brains were removed after killing by $5 \%$ halothane and stored in $10 \%$ formaldehyde. Probe placements within the NAC were subsequently verified from $50 \mu \mathrm{m}$ frozen, cresyl violet-stained sections. In all examined cases, at least $80 \%$ of the active portion of the dialysis membrane was located within the anatomical borders of the NAC (Fig. 1).

\section{Data analysis}

Differences in dialysate neurotransmitter concentrations among the DEPENDENT, NONDEPENDENT, and ETHANOL-NAIVE groups were analyzed by mixed factorial (Groups $\times$ Sampling Intervals) ANOVAs using separate analyses for DA and 5-HT. Dialysate fractions collected during the operant self-administration phase were analyzed for differences in monoamine concentrations relative to the final three samples of the withdrawal period, and for "percent of baseline" changes from mean DA and 5-HT concentrations over the last hour of withdrawal. After confirmation of significant main effects or interactions in the overall ANOVAs, differences among individual means were determined by Simple Fffects ANOVA and Duncan's Multiple Range post hoc tests. Ethanol self-administration data of the DEPENDENT and NONDEPENDENT rats were analyzed for differences in ethanol intake by two-tailed Student's $t$ test.

\section{RESULTS}

\section{Ethanol self-administration and behavioral observations \\ Operant self-administration training}

Forty-three rats were subjected to the saccharin-fading ethanol self-administration training procedure. As in previous work (Weiss et al., 1990; Weiss et al., 1993), the majority of the animals developed stable rates of ethanol self-administration with daily intakes sufficient to produce pharmacologically relevant BACs. Rats that failed to develop either significant or reliable daily ethanol intake $(n=11)$ were excluded from further training and testing. Mean \pm SEM 30 min ethanol consumption at the end of self-administration training was $0.72 \pm 0.10 \mathrm{gm} / \mathrm{kg}$ in rats subsequently assigned to the DEPENDENT $(n=11)$ condition, and $0.68 \pm 0.05 \mathrm{gm} / \mathrm{kg}$ in rats assigned to the NONDEPENDENT ( $n$ $=10$ ) group. Consumption of water was variable but remained on 


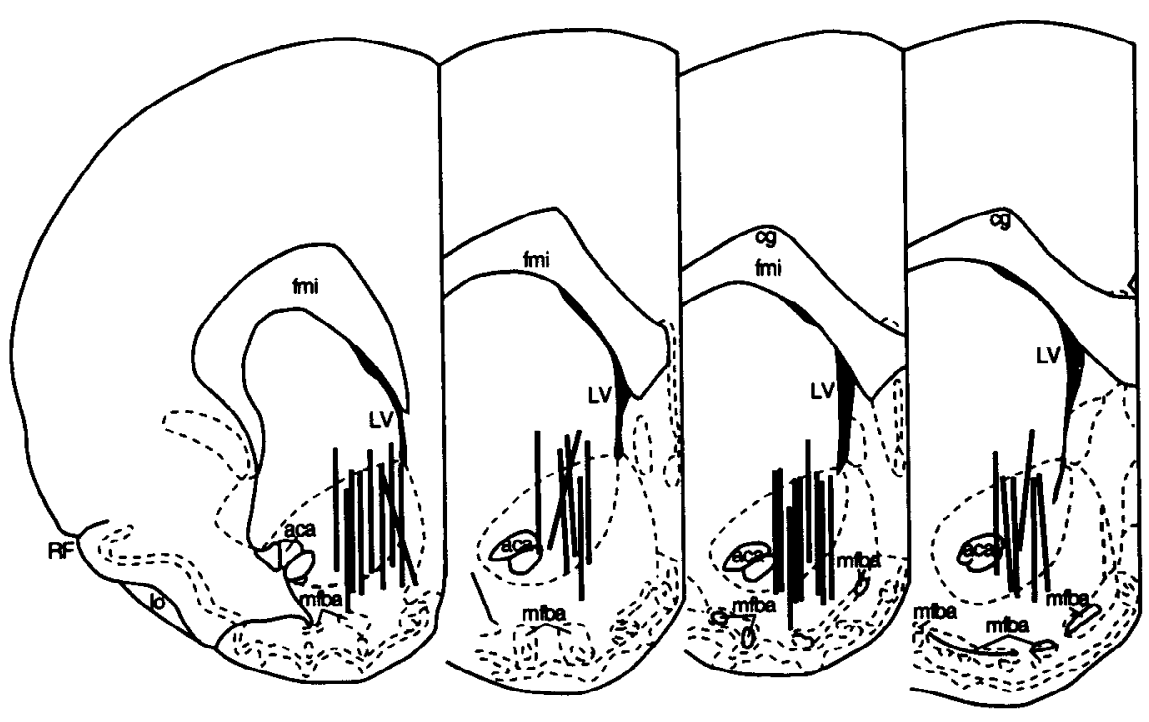

Figure 1. Anatomical location of the microdialysis probes. Vertical marks represent the "active" regions of the dialysis membranes. All probe placements were distributed between 1.20 and $2.20 \mathrm{~mm}$ anterior and $0.80-1.80 \mathrm{~mm}$ lateral to bregma. average below $40 \%$ of ethanol intake. All rats of the ETHANOLNAIVE $(n=11)$ control group successfully acquired responding for water but ceased responding in the absence of continued water deprivation during the baseline stage.

\section{Liquid diet}

Daily fluid consumption at the beginning of the liquid diet regimen ranged from approximately 70 to $80 \mathrm{ml} / \mathrm{d}$, corresponding to daily ethanol doses of 6.1-7.0 gm. Diet intake increased over the 3-5 weck treatment period to $100-120 \mathrm{ml} / \mathrm{d}$ (corresponding to 8.7-10.4 gm ethanol). Mean \pm SEM blood alcohol concentrations on days 3 or 4 after reexposure to the ethanol diet as measured between 2 and $3 \mathrm{hr}$ after replenishing drinking bottles with fresh liquid diet were $98.0 \pm 21.7 \mathrm{mg} \%$. No significant differences in mean \pm SEM body weights were noted at the end of exposure to the liquid diets among the DEPENDENT $(549.9 \pm 20.4 \mathrm{gm})$, pair-fed NONDEPENDENT $(503.8 \pm 5.4 \mathrm{gm})$, and control diet pair-fed ETHANOL-NAIVE $(463.5 \pm 32.3 \mathrm{gm})$ groups $\left(F_{(2,29)}=\right.$ 3.37; NS).

\section{Ethanol withdrawal}

Behavioral observation after removal of the ethanol diet confirmed the presence of a mild withdrawal syndrome similar to that described in other work using similar liquid diet procedures to induce ethanol dependence (Hunter et al., 1974; Merlo Pich et al., 1995; Schulteis et al., 1996). Although no specific quantitative measures were used, signs of withdrawal that were observed included hyperreactivity, occasional tremor, or stiffness of the tail.

\section{Effects of chronic ethanol on basal neurotransmitter levels}

Although DA and 5-HT were monitored simultaneously in the same animals, in some instances basal levels for one or both analytes remained below the limits of detection. Consequently, data for DA were not available for two rats in each of the DEPENDENT, NONDEPENDENT, and ETHANOL-NAIVE groups, whereas 5-HT data were not available for three DEPENDENT, two NONDEPENDENT, and three ETHANOL-NAIVE animals. The resulting samples sizes were $n=9 / 8(\mathrm{DA} / 5-\mathrm{HT})$ in the DEPENDENT, $n=8 / 8$ (DA/5-HT) in the NONDEPENDENT, and $n=9 / 8(\mathrm{DA} / 5-\mathrm{HT})$ in the ETHANOL-NAIVE groups.

The mean \pm SEM basal dialysate neurotransmitter concentra- tions as measured during the final $2 \mathrm{hr}$ of exposure to the control liquid diet in ETHANOL-NAIVE rats were $3.45 \pm 0.64 \mathrm{~nm}$ for DA and $1.15 \pm 0.22 \mathrm{~nm}$ for 5-HT. Compared to the ETHANOLNAIVE control group, basal dialysate DA levels were essentially unchanged in DEPENDENT rats with values of $3.90 \pm 0.68 \mathrm{~nm}$. In contrast, dialysate 5-HT concentrations were markedly elevated in these animals to $1.78 \pm 0.28 \mathrm{~nm}$ (see Fig. 3). Statistical analysis confirmed that 5 -HT efflux in DEPENDENT rats was significantly higher than in ETHANOL-NAIVE $(p<0.05)$ and NONDEPENDENT $(p<0.05)$ animals (Duncan's after ANOVA: $\left.F_{(2,21)}=3.98 ; p<0.03\right)$.

Whereas there were no differences in basal dialysate DA levels between DEPENDENT AND ETHANOL-NAIVE rats, DA efflux was substantially elevated in rats of the NONDEPENDENT group to $6.21 \pm 0.72 \mathrm{~nm}\left(F_{(2,23)}=4.76 ; p<0.02\right)$. Dialysate DA levels in this group were significantly higher than in both DEPENDENT $(p<0.05)$ and ETHANOL-NAIVE $(p<0.05)$ rats. No differences from ETHANOL-NAIVE controls were found in the mean \pm SEM basal 5-HT concentration of NONDEPENDENT rats, which was $0.97 \pm 0.11 \mathrm{~nm}$ (Fig. 2).

\section{Withdrawal-induced changes in DA and 5-HT levels}

Ethanol withdrawal was associated with a progressive decline in dialysate levels of both DA and 5-HT throughout the withdrawal period. Eight hr after ethanol, mean \pm SEM DA levels were decreased from $3.9 \pm 0.68 \mathrm{~nm}$ to $2.31 \pm 0.48 \mathrm{~nm}$ or $64.2 \pm 8.4 \%$ of prewithdrawal basal levels. A similar suppression occurred in 5-HT efflux, which was reduced from $1.78 \pm 0.26 \mathrm{~nm}$ to $0.89 \pm$ $0.15 \mathrm{~nm}$ or $55.1 \pm 10.6 \%$ of prewithdrawal concentrations. These data are summarized in Figure 3, which illustrates also that DA and 5-HT levels remained unaltered over this period in the ETHANOL-NAIVE and NONDEPENDENT groups. The withdrawal-induced suppression of neurotransmitter release was corroborated by significant interactions between Treatment Groups and Sampling Time for dialysate concentrations (DA: $\left.F_{(8,92)}=5.86 ; p<0.0001 ; 5-\mathrm{HT}: F_{(8,84)}=9.02 ; p<0.00001\right)$ and percent of prewithdrawal baseline values $\left(\mathrm{DA}: F_{(8,92)}=5.93 ; p<\right.$ $\left.0.0001 ; 5-\mathrm{HT}: F_{(8,84)}=4.28 ; p<0.0002\right)$. Subsequent analysis of simple effects (Sampling Time) confirmed significant decreases in dialysate concentrations $\left(\mathrm{DA} F_{(4,92)}=16.12 ; p<0.0001 ; 5-\mathrm{HT}\right.$ : $\left.F_{(4,84)}=23.38 ; p<0.0001\right)$ and percent of baseline levels (DA $\left.F_{(4,92)}=16.03 ; p<0.0001 ; 5-\mathrm{HT}: F_{(4,84)}=9.67 ; p<0.0001\right)$ over 


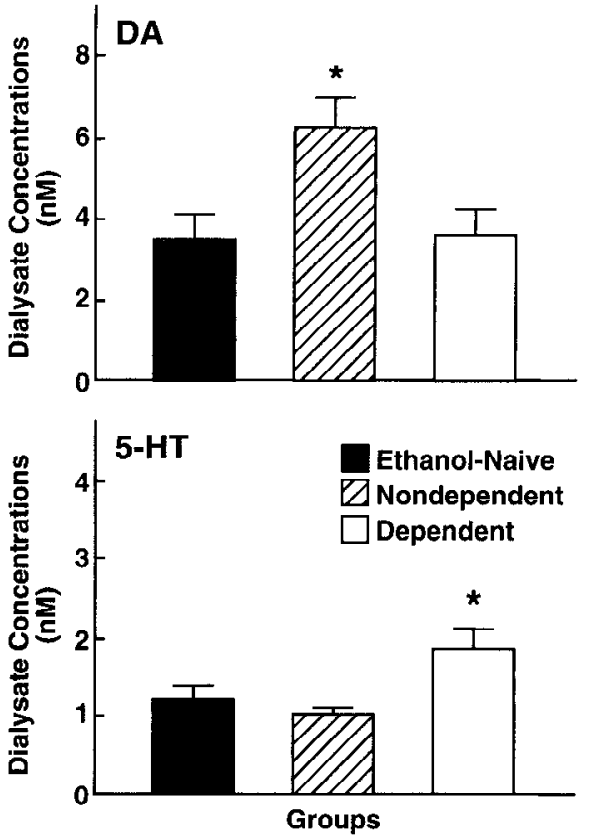

Figure 2. Top, Mcan \pm SEM dialysatc dopaminc concentrations monitorcd by microdialysis in the nucleus accumbens of DEPENDENT rats after exposure to chronic ethanol liquid diet, NONDEPENDENT but ethanol-exposed rats, and ETHANOL-NAIVE control animals. No differences in basal dopamine output from ethanol-naive rats were observed in dependent rats. However, basal dopamine release was substantially elevated in nondependent rats that had received limited-access exposure to ethanol during selfadministration training $\left({ }^{*} p<0.05\right.$; different from ETHANOL-NAIVE and DEPENDENT groups). Bottom, Dialysate serotonin concentrations in DEPENDENT, NONDEPENDENT, and ETHANOL-NAIVE rats. Basal 5 -HT efflux was significantly elevated in ethanol-dependent rats $\left({ }^{*} p<0.05\right.$; different from ETHANOL-NAIVE and NONDEPENDENT rats).

time in the DEPENDENT but not in the NONDEPENDENT or ETHANOL-NAIVE groups.

\section{Effects of ethanol self-administration on DA and 5-HT release}

\section{Operant self-administration}

The mean \pm SEM 60 min volumes and amounts of operantly self-administered ethanol at the end of the $8 \mathrm{hr}$ withdrawal period were $5.55 \pm 0.78 \mathrm{ml}$ or $0.95 \pm 0.14 \mathrm{gm} / \mathrm{kg}$ in dependent rats. Ethanol intake in this group greatly exceeded that in nondependent rats of the ethanol-acclimated, nondependent group, which was $2.90 \pm 0.55 \mathrm{ml}$ or $0.57 \pm 0.10 \mathrm{gm} / \mathrm{kg}$ (Fig. 4). The greater ethanol consumption in the DEPENDENT over the NONDEPENDENT group was confirmed by statistical analysis $\left(t_{19}=2.25\right.$; $p<0.05)$.

In some animals only one of the two neurotransmitters was detectable at the beginning of self-administration. The DEPENDENT group (original $n=11$ ) included three rats for which data on either DA or 5-HT but not both analytes were available for statistical comparison. Mean alcohol consumption in the DA and 5-HT "groups" resulting from the "asymmetry" in the detectability of the two transmitters was identical over the $1 \mathrm{hr}$ session (DA: $0.93 \pm 0.44 \mathrm{gm} / \mathrm{kg} ; 5$-HT: $0.95 \pm 0.18 \mathrm{gm} / \mathrm{kg}$ ) although there was a difference in the distribution of ethanol intake over time (Fig. $5 E$ ). In the NONDEPENDENT group (original $n=10$ ), DA levels were below the detection limit in three, and 5-HT concentrations in four animals. Among ETHANOL-NAIVE rats (origi- nal $n=11$ ), DA was not detectable in two, whereas 5-HT remained undetectable in three animals. The resulting sample sizes for this part of the experiment were as follows: DEPENDENT (DA/5-HT: $n=8 / 8$ ), NONDEPENDENT (DA/5-HT: $n=$ 7/6), ETHANOL-NAIVE (DA/5-HT: $n=9 / 8$ ).

No significant changes in DA or 5-HT concentrations were noted at any time in the dialysates of ETHANOL-NAIVE control rats given the opportunity to respond for water. In contrast, self-administration of ethanol reliably increased DA and 5-HT efflux (Fig. 5). In DEPENDENT rats undergoing withdrawal, self-administration of ethanol produced a $200-250 \%$ rise in DA efflux over withdrawal levels. In fact, ethanol restored DA efflux in these animals to prewithdrawal levels within the first 10 min of self-administration. Moreover, once restored, extracellular DA concentrations were maintained at these levels by ethanol intake for the remainder of the $1 \mathrm{hr}$ test. Rapid increases of up to $145 \%$ of withdrawal levels were also noted in 5-HT efflux after the onset of self-administration in dependent rats. However, ethanol failed to effectively restore extracellular 5-HT concentrations to values recorded before withdrawal. The effects of alcohol selfadministration on DA release were confirmed by significant Groups $\times$ Sampling Time interactions for both dialysate concentrations $\left(F_{(20,210)}=2.45 ; p<0.001\right)$ and percent of baseline levels $\left(F_{(16,168)}=3.27 ; p<0.0001\right)$, and by subsequent Simple Effects ANOVAs of changes across Sampling Time in the DEPENDENT group alone (dialysate concentrations: $F_{(10,210)}=5.28 ; p<$ 0.0001 ; percent of baseline data: $\left.F_{(10,210)}=4.32 ; p<0.0001\right)$. Alcohol-induced increases in 5-HT efflux were similarly confirmed by significant Groups $\times$ Sampling Time interactions (dialysatc concentrations: $\left.F_{(20,190)}=1.67 ; p<0.05\right)$ or a main effect of Groups (percent of baseline changes: $F_{(8,152)}=3.9 ; p<0.0005$ ) in the overall ANOVA, followed by analysis of simple effects of Sampling Time (dialysate concentrations: $F_{(10,190)}=3.27 ; p<$ 0.001 ; percent of baseline: $\left.F_{(8,152)}=3.59 ; p<0.001\right)$ in DEPENDENT rats.

Ethanol self-administration also produced a transient increase in mean \pm SEM efflux of DA and 5-HT in the NONDEPENDENT group reaching $130 \pm 4.0 \%$ (DA) and $141 \pm 25.2 \%$ (5-HT) of basal values (Fig. $5 C$ ). This effect was confirmed by analyses of simple effects after overall ANOVA (above), which revealed reliable differences in either dialysate concentrations (DA: $\left.F_{(2,210)}=4.32 ; p<0.0001\right)$ or percent of baseline data $\left(5-\mathrm{HT}: F_{(8,152)}=2.00 ; p<0.05\right)$ across Sampling Time.

\section{Reintroduction of liquid diets}

After completion of the operant self-administration test, the effects of reexposure to the ethanol-containing and control liquid diets were examined over a $1 \mathrm{hr}$ period in several randomly selected DEPENDENT $(n=5)$ and ETHANOL-NAIVE $(n=7)$ rats. During this time of renewed availability of the ethanol liquid diet, DA efflux decreased somewhat from the levels attained during operant self-administration which were slightly (but nonsignificantly) elevated relative to the prewithdrawal baseline (Fig. 6 ). The mean \pm SEM dialysate DA concentrations during the first hour of postwithdrawal access to the ethanol diet $(3.65 \pm 0.71 \mathrm{nM})$ was significantly different from withdrawal levels $(2.24 \pm 0.74 \mathrm{nM}$; planned comparison after overall ANOVA: $F_{(3,39)}=5.24 ; p<$ 0.01 ) but remained statistically indistinguishable from basal levels recorded in these animals before ethanol withdrawal $(3.98 \pm 0.97$ $\mathrm{nM})$ and from ETHANOL-NAIVE rats $(4.14 \pm 0.53)$.

Dialysate 5-HT concentrations in the DEPENDENT group increased after re-exposure to the ethanol liquid diet to levels 
above those recorded during operant self-administration $(1.25 \pm$ 0.22 vs $1.46 \pm 0.13$ nM; Fig. 6). Although mean 5 -HT efflux did not reach prewithdrawal levels $(1.46 \pm 0.13$ vs $2.01 \pm 0.41 \mathrm{nM})$, statistical differences between pre- and postwithdrawal 5-HT were no longer apparent after access to the ethanol liquid diet.

No differences from DA and 5-HT baseline levels were recorded in NONDEPENDENT rats given access to control diet after operant self-administration (data not shown).

\section{DISCUSSION}

The results confirm that ethanol self-administration increases the extracellular levels of DA and 5-HT in the NAC, two neurotransmitters that have been implicated in the acute pharmacological and reinforcing actions of ethanol, whereas ethanol withdrawal is accompanied by a significant suppression in the release of these monoamines. The results also indicate that dependent rats will "work" during withdrawal to obtain ethanol in an operant selfadministration task, and that ethanol consumption reverses the withdrawal-associated extraneuronal DA and 5-HT deficits.

Of central interest in this study was the exploration of the involvement of DA and 5-IIT in the reinforcing effects of alcohol in dependent subjects. It has traditionally been difficult to demonstrate that ethanol withdrawal motivates ethanol-seeking behavior in animals (for review, see Cicero, 1980; Grant et al., 1990; Meisch and Stewart, 1994), although positive results have been obtained in rats given the opportunity to associate ethanol intake with the alleviation of withdrawal symptoms over multiple episodes of forced abstinence (Hunter et al., 1974). However, it was recently shown that with appropriate ethanol-initiation procedures rats will self-administer significant amounts of ethanol even during their first withdrawal experience (Schulteis et al., 1996).

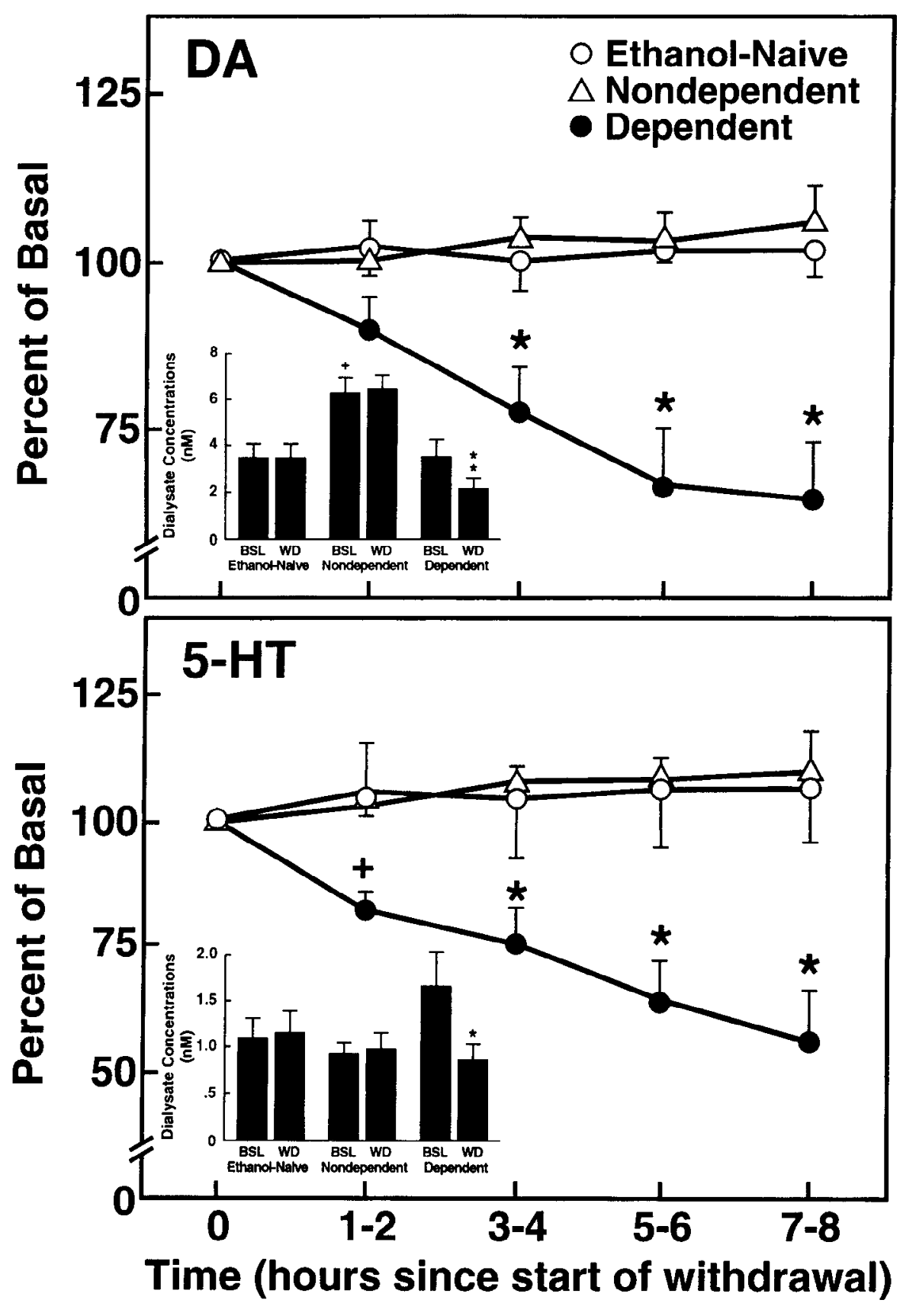

Figure 3. Dopamine (top) and serotonin (bottom) efflux during the final hour of exposure to ethanol liquid diet (DEPENDENT) or equicaloric control diet (NONDEPENDENT and ETHANOLNAIVE) and a subsequent $8 \mathrm{hr}$ withdrawal period. Data are presented as mean \pm SEM percent of basal values across sets of three successive $20 \mathrm{~min}$ samples collected at $2 \mathrm{hr}$ intervals $\left[{ }^{*} p<0.01\right.$; different from basal (Time 0) levels]. Insets, Mean \pm SEM DA (top) and 5-HT (bottom) dialysate concentrations in DEPENDENT, NONDEPENDENT, AND ETHANOL-NAIVE rats. The concentration data correspond to prewithdrawal baseline (time 0 ) and $7-8 \mathrm{hr}$ withdrawal points of the percent of baseline data above. Ethanol withdrawal was associated with a significant reduction in dialysate levels of both DA and 5-HT $\left[{ }^{*} F_{(1,23)}=23.02\right.$, $p<0.001 ;{ }^{*} F_{(1,21)}=13.46, p<0.0001$. Different from respective DEPENDENT prewithdrawal baseline (BSL); simple effects ANOVAs]. Note also the persistent elevation in basal DA output in NONDEPENDENT, ethanol-acclimated rats $\left[{ }^{+} p\right.$ $<0.05$; different from both DEPENDENT and ETHANOL-NAIVE baseline (BSL)]. 
The present results confirm this observation and provide a possible neurochemical basis for the reinforcing effects of ethanol in dependent rats. In particular, the data suggest that the rats regulated their ethanol intake during both operant self-administration and subsequent liquid diet consumption in a manner that restored and maintained DA efflux at prewithdrawal levels. In a previous report, an intragastric ethanol challenge dose was shown to restore deficient DA release in the ventral striatum and to reverse ethanol withdrawal symptoms (Rossetti et al., 1992). The apparent behavioral "titration" of ethanol intake to regain prewithdrawal conditions in the present experiment extends this finding by implicating accumbal DA release in ethanol-maintained reinforcement in dependent subjects and, by extension, in continued abuse and dependence.

In contrast to DA, 5-HT levels recovered only partially during operant ethanol self-administration. Several explanations may account for this finding. It is possible that in contrast to its acute effects in nondependent rats, ethanol exerts a more gradual or delayed effect on 5-HT release in dependent rats, although this seems unlikely because ethanol produced a rapid initial increase in 5-HT efflux within $10 \mathrm{~min}$ of the onset of self-administration. Alternatively, 5-HT synthesis and/or release mechanisms may become compromised over the course of chronic ethanol exposure or during withdrawal, resulting in an overall decreased responsivity to the effects of ethanol as suggested, for example, by the attenuation of ethanol effects on accumbal 5-HIAA levels in ethanol-tolerant $\mathrm{P}$ rats (Murphy et al., 1988). A third interpretation is related to the observation that prewithdrawal 5-HT levels in the dependent group were substantially elevated relative to ethanol-naive rats. If the adaptive changes that underlie the enhancement in 5-HT release by chronic ethanol are short-lived and undergo rapid reversal during withdrawal, a full restoration to prewithdrawal levels would not be expected. In fact, in this case the "partial" restoration of 5-HT efflux may amount functionally to a "full" restoration.

Considering the implications of the 5-HT data for the motivational effects of ethanol withdrawal, it is likely that the reversal of a neurotransmitter deficit-even if only partial--that underlies withdrawal distress promotes ethanol-seeking behavior. Indeed, in reviewing the literature, LeMarquand and colleagues (LeMarquand et al., 1994) conclude that decreased functional activity of 5-HT systems that accompanies ethanol withdrawal may produce the biochemical conditions for a resumption of ethanol intake. However, the specific role of accumbal 5-HT in the affective changes that accompany ethanol withdrawal remains to be established. Alcohol preference in genetically selected rats of the Indiana $\mathrm{P}$ and $\mathrm{HAD}$ lines has been linked to reduced functional activity of 5-HT neurotransmission in the NAC (Murphy et al., 1982, 1987; Gongwer et al., 1989; McBride et al., 1990), and these rats show a heightened anxiogenic response in a variety of behavioral measures of anxiety (Stewart et al., 1993). To the extent that accumbal serotonergic deficits underlie the heightened anxiety of these animals, one may speculate that the affective conditions that motivate ethanol drinking in alcohol preferring rats and the resumption of drinking during withdrawal share a common neurochemical basis.

The progressive decline in extracellular DA and 5-HT during the $8 \mathrm{hr}$ ethanol withdrawal period preceding the self-administration session extends previous obscrvations of withdrawal-associated decreases in striatal DA turnover and whole tissue content (Gil et al., 1992), as well as reductions in 5-HT metabolism and content of 5-HT or its metabolite, 5-hydroxyindoleacetic acid (5-HIAA), in rodent

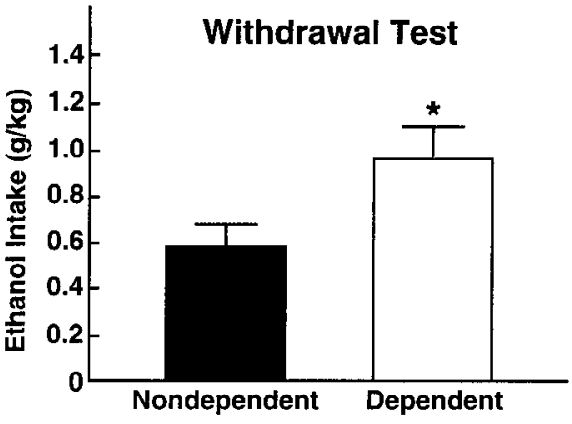

Figure 4. Alcohol intake during a 60 min operant self-administration session in (DEPENDENT, $n=10$ ) and (NONDEPENDENT, $n=11$ ) rats measured $8 \mathrm{hr}$ after removal of ethanol or control liquid diet. The amount of self-administered alcohol during the withdrawal test was significantly greater in dependent than in nondependent rats $\left({ }^{*} p<0.05\right.$; significantly different from nondependent rats, Student's $t$ test)

whole brain, limbic, and striatal tissue preparations (Kahn and Scudder, 1976; Tabakoff et al., 1977; Badawy and Evans, 1983; Kempf et al., 1990; Wahlström et al., 1991; Yamamura et al., 1992). More importantly, these results localize withdrawal-associated deficiencies in monoamine function to a brain reward region that has been implicated in the acute reinforcing effects of alcohol and other substances of abuse.

With respect to the mechanisms that regulate the release or extraneuronal concentrations of DA and 5-HT in the NAC, these data are suggestive of the development of a "within-systems adaptation" during the course of chronic ethanol exposure such that the same neurochemical systems that are activated by the acute pharmacological actions of ethanol exhibit a functional deficit in the absence of continued stimulation by the drug (Koob and Bloom, 1988). Alcohol acutely increases the firing rate of $\mathrm{A}$ 10 ventral tegmental DA neurons (Gessa et al., 1985; Brodie et al., 1990) whereas A 10 neuronal activity is drastically inhibited during ethanol withdrawal (Diana et al., 1992, 1993). Thus, the failure to observe an elevation of prewithdrawal DA levels in animals exposed to the ethanol liquid diet over those in ethanol-naive rats (Fig. 3), in conjunction with the precipitous fall in DA efflux once ethanol was removed, may reflect a suppression in mesoaccumbens DA activity to "balance" chronic stimulation by ethanol. Adaptive changes at the biochemical level may also serve as mechanisms both for the lack of differences between dependent and ethanol-naive rats in prewithdrawal DA release, and the reduction in extraneuronal DA during withdrawal. For example, chronic-ethanol exposure suppresses $\mathrm{K}^{+}$-stimulated DA release (Darden and Hunt, 1977) presumably via inhibition of $\mathrm{Ca}^{2+}$ influx (Kim et al., 1994) or by uncoupling of calcium entry and DA release (Leslie et al., 1986). More importantly, whereas acute ethanol administration stimulates DA synthesis, this effect is blunted in chronically ethanol-treated animals (Tabakoff and Hoffman, 1978; Fadda et al., 1980).

A neuroadaptive account may be less obvious in the case of 5-HT, where prewithdrawal (i.e., chronic ethanol-stimulated) levels were elevated relative to both ethanol-naive and nondependent rats, a finding that corroborates earlier data demonstrating that chronic ethanol treatments increase forebrain tissue levels of 5-HT and 5-HIAA (Tytell and Myers, 1973; Mena and Herrera, 1980; Hunt and Majchrowicz, 1983; Morinan, 1987; Kaneyuki et al., 1991). However, it is known that the increase in brain 5-HIAA content produced by an ethanol challenge is reduced in ethanol- 

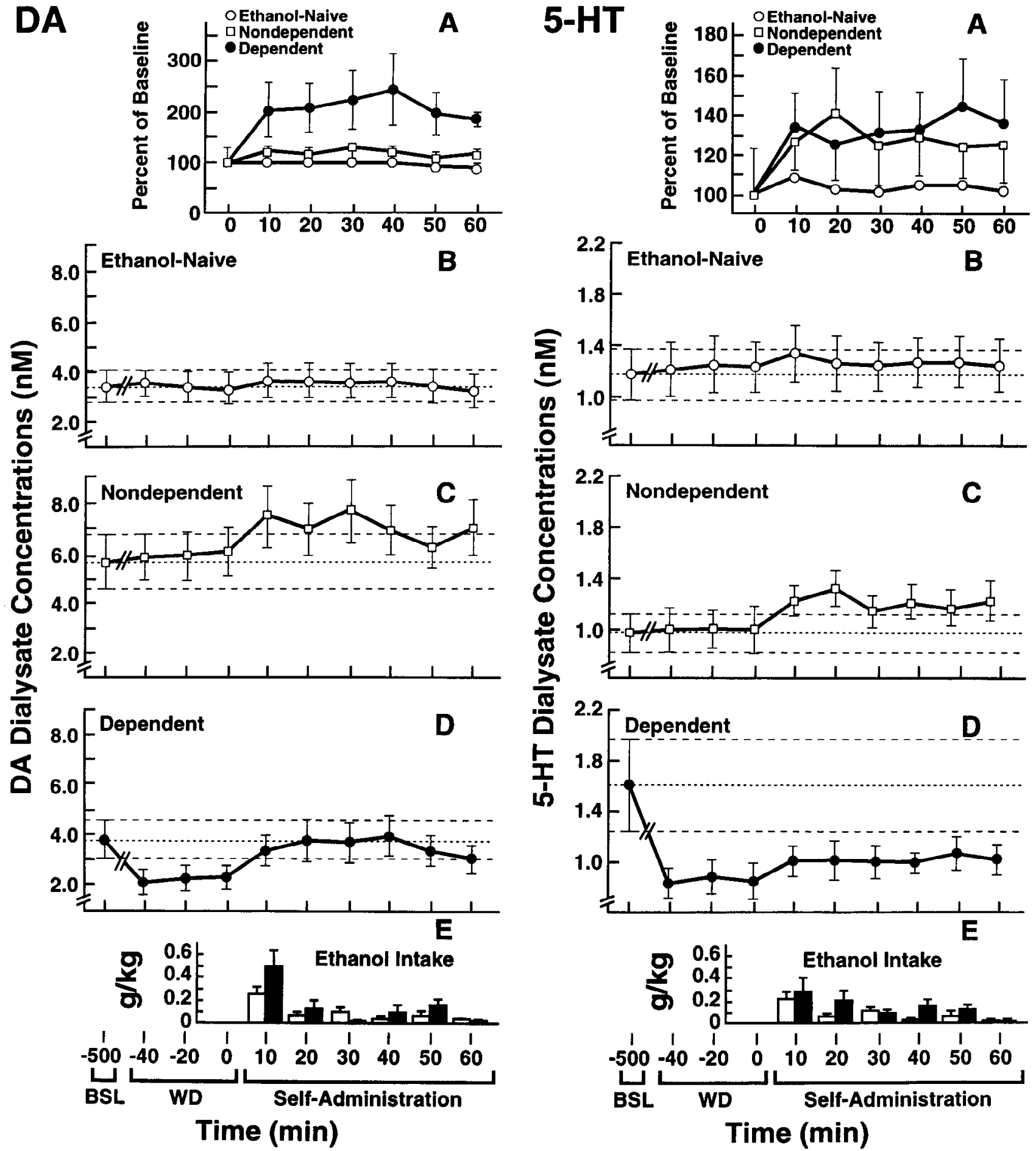

Figure 5. Effects of operant alcohol self-administration in NONDEPENDENT and DEPENDENT rats undergoing ethanol withdrawal on DA and 5-HT efflux in the nucleus accumbens. Dialysate neurotransmitter levels are compared to those in ETHANOL-NAIVE rats trained to self-administer water. Average water intake in this group was negligible $(<0.8 \mathrm{ml})$ and is not shown. $A$. Changes in neurotransmitter output from levels recorded during the last hour of withdrawal. Data are expressed as percent of baseline values calculated as the average of three 20 min samples collected during hour 8 of withdrawal shown in $B-D$. The corresponding dialysate neurotransmitter concentrations are shown in $B$ (ETHANOL-NAIVE), $C$ (NONDEPENDENT), and $D$ (DEPENDENT). To illustrate the changes in neurotransmitter efflux over the various experimental phases, $B-D$ also show prewithdrawal $(B S L)$ and withdrawal $(W D)$ dialysate concentrations of DA and 5-HT during hr 8 of withdrawal. Dashed lines represent mean \pm SEM prewithdrawal dialysate DA or 5-HT concentrations. E, Amounts of self-administered ethanol $(10 \% \mathrm{w} / \mathrm{v})$ during $10 \mathrm{~min}$ intervals for the DEPENDENT (solid bars) and NONDEPENDENT (open bars) groups. Ethanol self-administration in DEPENDENT rats restored DA levels to prewithdrawal values. In contrast, ethanol self-administration failed to reinstate 5-HT concentrations to prewithdrawal levels. However, ethanol effectively restored 5-HT release to levels comparable to those in the ETHANOL-NAIVE control group (for statistical comparisons, see Results). 

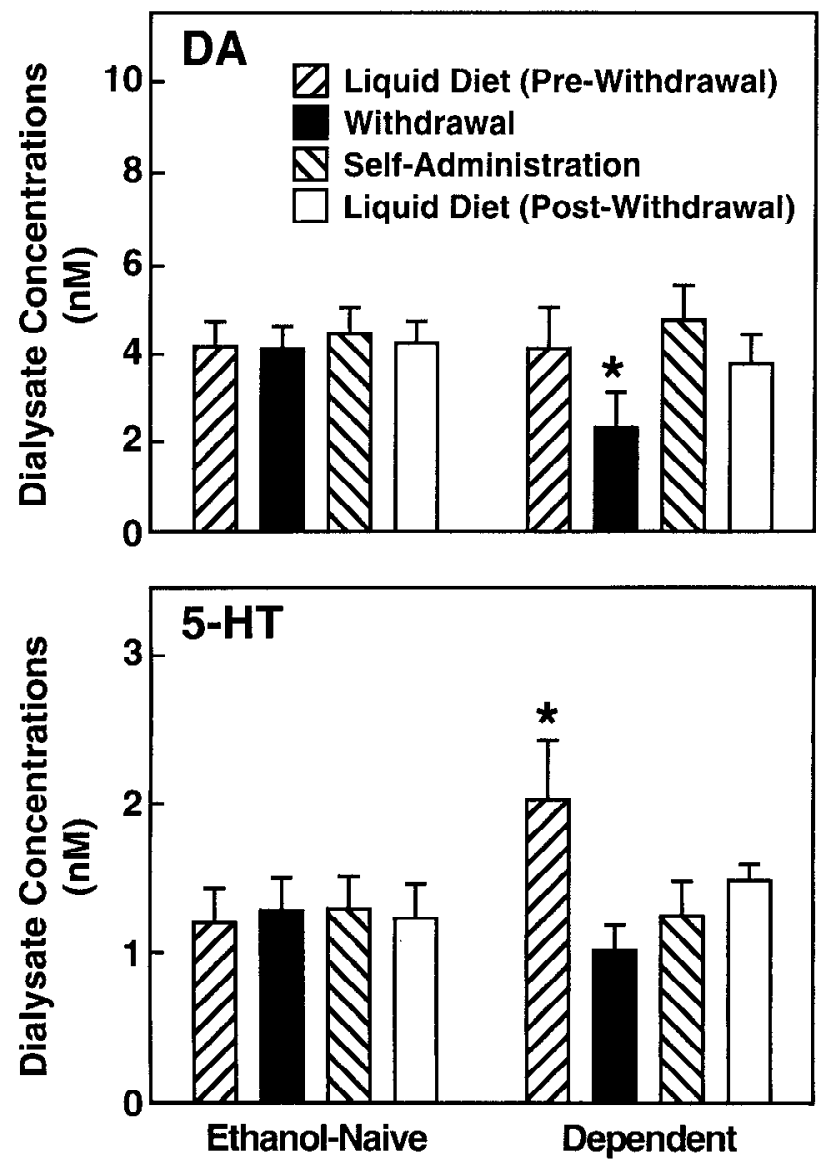

Figure 6. Effects of reexposure to ethanol and control liquid diets on DA and 5-HT levels in DEPENDENT $(n=5)$ and ETHANOL-NAIVE $(n=$ 7) rats. For comparison, monoamine levels during prewithdrawal, withdrawal (hour 8), and operant self-administration conditions are also included. All data represent $1 \mathrm{hr}$ averages during the respective stages. $\left[{ }^{*} D A\right.$, Different from Pre-Withdrawal $(p<0.05)$ and Self-Administration $(p$ $<0.01)$ and different from corresponding condition in ETHANOLNAIVE rats $(p<0.05)$. 5-HT, Different from Withdrawal and SelfAdministration $(p<0.05)$ and different from corresponding ETHANOLNAIVE condition $(p<0.001])$.

tolerant alcohol-preferring $(\mathrm{P})$ rats, particularly in the NAC (Murphy et al., 1988; McBride et al., 1990). Thus, it is possible that the increased 5-HT efflux at the end of the chronic ethanol regimen was reduced (i.e., showed an adaptive attenuation) relative to the initial serotonergic response to the ethanol diet. Although this hypothesis awaits confirmation, the suppression of 5-HT release during the withdrawal stage was clearly suggestive of the presence of neuroadaptive changes in 5-HT function in response to chronic ethanol.

The extracellular monoamine deficits in the NAC, then, may underlie certain alcohol withdrawal symptoms, in particular, affective changes that are opposite to those produced by ethanol acutely. Ethanol can enhance brain stimulation reward acutely (a phenomenon dependent, at least in part, on the functional integrity of mesolimbic DA transmission) (Moolten and Kornetsky, 1990; Lewis, 1991), whereas ethanol withdrawal is accompanied by a reward deficit as measured by elevations in intracranial self-stimulation thresholds (Schulteis et al., 1995). There is also some evidence that 5-HT activation can support or potentiate brain stimulation reward (Gibson et al., 1970; Miliaressis et al.,
1975; Redgrave and Horrell, 1976). Thus, an extraneuronal deficit of this transmitter may be expected to exacerbate a DAdependent reward deficit, particularly so in light of recent cvidence of a facilitatory role of 5-HT on DA release in the NAC (Chen et al., 1991; Devaud and Hollingsworth, 1991; Yoshimoto and McBride, 1992; Parsons and Justice, 1993). In this context, it is interesting to note that the progression of the extracellular deficits in the present study paralleled closely the emergence and temporal profile of behavioral withdrawal symptoms in related work, including brain stimulation reward deficits, hyperirritability, behavioral inhibition, and anxiogenic effects (Baldwin et al., 1991; Rassnick et al., 1992; Schulteis et al., 1995). Thus, the synchronous emergence of these behavioral and neurochemical changes may be reflective of a role for DA and 5-HT in the negative affective conditions that accompany ethanol withdrawal.

Although the role of DA and 5-HT in ethanol reward and dependence was of primary concern in the present study, the effects of ethanol self-administration on the release of these transmitters in nondependent rats are also interesting. The increase in DA release in the nondependent group confirms a previous report (Weiss et al., 1993) and further supports the role of DA in the acute reinforcing actions of ethanol. Of special importance, however, was the observation that self-administration of ethanol by nondependent rats increased 5-HT efflux since these results extend findings of increased 5-HT release in the NAC after systemic and local alcohol administration (Yoshimoto et al., 1991, 1992) to a possible role for $5-\mathrm{HT}$ in the acute reinforcing actions of ethanol.

The finding that basal DA output was substantially elevated in NONDEPENDENT rats, compared to both the ETHANOLNAIVE and DEPENDENT groups was surprising since the nondependent animals had not received access to ethanol for 2-3 weeks - while placed on the control liquid diet-before the microdialysis test. One possibility to explain this observation is that intermittent access to alcohol can lead to a persistent elevation in basal DA release. Alternatively, this finding may be a attributable to the selection of experimental versus control animals. Ethanoltrained rats were assigned to the NONDEPENDENT or DEPENDENT groups only if they met a selection criterion (stable daily ethanol intake of $\geq 0.5 \mathrm{gm} / \mathrm{kg}$ ethanol intake), whereas all ETHANOL-NAIVE rats were tested indiscriminately. If it is assumed that there is a dopaminergic "abnormality" that predisposes rats toward heightened ethanol intake, this selection process may have introduced a "neurochemical bias" toward enhanced basal DA release in the DEPENDENT and NONDEPENDENT samples. By this account, the enhanced DA efflux in NONDEPENDENT rats may be a consequence of the selection procedure that favored inclusion of subjects with this neurochemical characteristic. Given the differences in basal DA efflux between the DEPENDENT and NONDEPENDENT groups, this account would also invoke the conclusion that chronic ethanol leads to a suppression of basal DA release in this population of rats.

Several considerations argue against this interpretation, however. The absence of differences in extracellular DA between ETHANOL-NAIVE and DEPENDENT rats data are in good agreement with previous in vitro studies that have demonstrated that chronically ethanol-treated animals do not differ from untreated controls in striatal or accumbal DA synthesis and DOPAC levels (Tabakoff and Hoffman, 1978; Fadda et al., 1980; Patel and Pohorecky, 1989; Gil et al., 1992). Given the consistency between the present and these earlier whole-tissue data (which have used 
some form of forced ethanol administration and, thus, did not involve a potential selection bias), it seems unlikely that the current selection procedures alone can account for the enhanced DA release in the NONDEPENDENT group. More direct support for the possibility that this effect is related to intermittent ethanol consumption, rather than a selection bias, comes from recent work in this laboratory showing that randomly selected Wistar rats subjected to repeated intraperitoneal ethanol injections had profoundly increased basal extracellular DA concentrations in the NAC as measured $24 \mathrm{hr}$ after the final ethanol treatment (A. D. Smith and F. Weiss, unpublished observations). On the other hand, although these data support the hypothesis that repeated ethanol exposure can elevate basal DA efflux in the NAC, the persistent enhancement in basal DA efflux in the NON. DEPENDENT group clearly requires confirmation and the potential significance of this finding for ethanol-seeking behavior remains to be clarified.

In conclusion, the results suggest that two neurotransmitter systems that are thought to mediate alcohol's acute reinforcing properties may also play a role in the reinforcing actions of alcohol in dependent subjects. These results lend support for neuroadaptation theories that view withdrawal as resulting from physiological changes within brain reward circuitries that become manifest as drug-opposite responses once exposure to the drug is terminated.

\section{REFERENCES}

Badawy AB, Evans M (1983) Opposite effects of chronic administration and subsequent withdrawal of drugs of dependence on the metabolism and disposition of endogenous and exogenous tryptophan in the rat. Alcohol 18:369-382.

Baldwin HA, Rassnick S, Rivier J, Koob GF, Britton KT (1991) CRF antagonist blocks alcohol withdrawal "anxiogenic" response. Psychopharmacology 103:227-232.

Brodie MS, Shefner SA, Dunwiddie TV (1990) Ethanol increases the firing rate of dopamine neurons of the rat. Brain Res 508:65-69.

Chen J, van Praag HM, Gardner EL (1991) Activation of 5- $\mathrm{HT}_{3}$ receptors by 1-phenylbiguanide increases dopamine release in the nucleus accumbens. Brain Res 543:354-357.

Cicero TJ (1980) Alohol self-administration, tolerance and withdrawal in humans and animals. Theoretical and methodological issues. In: Alcohol tolerance and dependence, pp 1-51. New York: Elsevier.

Cloninger CR (1987) Neurogenetic and adaptive mechanisms in alcoholism. Science 236:410-416.

Darden JH, Hunt WA (1977) Reduction of striatal dopamine release during an ethanol withdrawal syndrome. J Neurochem 29:1143-1145.

Devaud LI, Hollingsworth FB (1991) Effects of the 5-HT2 receptor antagonist, ritanserin, on biogenic amines in the rat nucleus accumbens. Eur J Pharmacol 192:427-429.

Diana M, Pistis M, Carboni S, Gessa GL, Rossetti ZL (1992) Profound decrement of mesolimbic neuronal activity during ethanol withdrawal syndrome in rats: electrophysiological and biochemical evidence. Proc Natl Acad Sci USA 90:7966-7969.

Diana M, Pistis M, Muntoni A, Rossetti ZL, Gessa G (1993) Marked decrease of A10 dopamine neuronal firing during ethanol withdrawal syndrome in rats. Eur $\mathrm{J}$ Pharmacol 221:403-404.

Engel JA, Enerback C, Fahlke C, Hulthe P, Hard E, Johannessen K, Svensson L, Soderpalm B (1992) Serotonergic and dopaminergic involvement in ethanol intake. In: Novel pharmacological interventions for alcoholism, pp 68-82. New York: Springer.

Fadda F, Argiolas A, Melis MR, Serra G, Gessa GL (1980) Differential effect of acute and chronic ethanol on dopamine metabolism in frontal cortex, caudate nucleus and substantia nigra. Life Sci 27:979-986.

Fadda F, Mosca E, Colombo G, Gessa GL (1989) Effects of spontaneous ingestion of ethanol on brain dopamine metabolism. Life Sci 44:281-287.

Froehlich JC, Li T-K (1993) Opioid Peptides. In: Recent developments in alcoholism, Vol 11, Ten years of progress. New York: Plenum.
Gatto GJ, McBride WJ, Murphy JM, Lumeng L, Li T-K (1994) Ethanol self-infusion into the ventral tegmental area by alcohol-preferring $(P)$ rats. Alcohol 11:557-564.

Gessa GL, Muntoni F, Collu M, Vargiu L, Mereu G (1985) Low doses of ethanol activate dopaminergic neurons of the ventral tegmental area. Brain Res 248:210-204.

Gianoulakis C (1989) The effect of ethanol on the biosynthesis and regulation of opioid peptides. Experientia 45:428-435.

Gibson S, McGeer EG, McGeer PL (1970) Effect of selective inhibitors of tyrosine and tryptophan hydroxylases on self-stimulation in the rat. Exp Neurol 27:283-290.

Gil E, Colado I, Lopez F, Fernandez-Briera A, Fernandez-Lopez A, Calvo P (1992) Effects of chronic treatment with ethanol and withdrawal of ethanol on levels of dopamine, 3,4-dihydroxyphenylacetic acid and homovanillic acid in the striatum of the rat. Influence of benzodiazepines, barbiturate and somatostatin. Neuropharmacology 31:1151-1156.

Gongwer MA, Murphy JM, McBride WJ, Lumeng L, Li TK (1989) Regional brain contents of serotonin, dopamine and their metabolites in the selectively bred high- and low-alcohol drinking lines of rats. Alcohol 6:317-320.

Gorelick D (1989) Serotonin uptake blockers and the treatment of alcoholism. In: Recent developments in alcoholism: treatment rescarch. New York: Plenum.

Grant KA (1994) Emerging neurochemical concepts in the actions of ethanol at ligand-gated ion channels. Behav Pharmacol 5:383-404.

Grant KA, Barrett JE (1991) Blockade of the discriminative stimulus effects of ethanol with $5-\mathrm{HT}_{3}$-receptor antagonists. Psychopharmacology 104:451-456.

Grant KA, Colombo G (1993) Substitution of the 5-HT, agonist trifluoromethylphenylpiperazine (TFMPP) for the discriminative stimulus effects of ethanol: effect of training dose. Psychopharmacology 113:26-30.

Grant KA, Hoffman P, Tabakoff B (1990) Neurobiological and behavioral approaches to tolerance and dependence. In: The nature of dependence, pp 135-169. Oxford: Oxford UP.

Greenfield TK, Weisner C (1995) Drinking problems and self-reported criminal behavior, arrests and convictions: 1990 U.S. alcohol and 1989 county surveys. Addiction 90:361-367.

Hodge CW, Haraguchi M, Erickson H, Samson HH (1993) Ventral tegmental microinjections of quinpirole decrease ethanol and sucrose reinforced responding. Alcohol Clin Exp Res 17:370-375.

Hoffman PL, Ishizawa H, Giri PR, Dave JR, Grant KA, Liu L-I, Gulya K, Tabakoff B (1990) The role of arginine vasopressin in alcohol tolerance. Ann Med 22:269-274.

Hunt WA (1993) Neuroscience rescarch: how has it contributed to our understanding of alcohol abuse and alcoholism. Alcohol Clin Exp Res 17:1055-1065.

Hunt WA, Majchrowicz E (1983) Studies of neurotransmitter interactions after acute and chronic ethanol administration. Pharmacol Biochem Behav 18[Suppl 1]:371-374.

Hunter BE, Walker DW, Riley JN (1974) Dissociation between physical dependence and volitional ethanol consumption: role of multiple withdrawal episodes. Pharmacol Biochem Behav 2:523-529.

Imperato A, DiChiara G (1986) Preferential stimulation of dopamine release in the nucleus accumbens of freely moving rats by ethanol. J Pharmacol Exp Ther 239:219-239.

Kahn AJ, Scudder CL (1976) Alcohol withdrawal effects on brain serotonin in mice behaviorally attracted to alcohol. J Stud Alcohol 37:1572-1580.

Kaneyuki T, Morimasa T, Okada H, Shohmori T (1991) The effects of acute and repeated ethanol administration on monoamines and their metabolites in brain regions of rats. Acta Med Okayama 45:201-208.

Kempf E, Kempf J, Ebel A (1990) Alcohol withdrawal-induced changes in brain biogenic amines in mice: influence of the genotype. Neurochem Res 15:69-75.

Kim W-K, Johnson RG, Izu LT, Rabin RA (1994) Chronic ethanol exposure inhibits ATP-stimulated but not KCl-stimulated dopamine relcase in PC12 cclls. J Pharmacol Exp Ther 270:336-341.

Koob GF, Bloom FE (1988) Cellular and molecular mechanisms of drug dependence. Science 242:715-723.

Krystal JH, Webb E, Cooney N, Kranzler HR, Charney DS (1994) Specificity of ethanol-like effects elicited by serotonergic and noradrenergic mechanisms. Arch Gen Psychiatry 51:898-911. 
LeMarquand D, Pihl RO, Benkelfat C (1994) Serotonin and alcohol intake, abuse, and dependence: findings of animal studies. Biol Psychiatry $36: 395-421$.

Leslie SW, Woodward JJ, Wilcox RE, Farrar RP (1986) Chronic ethanol treatment uncouples striatal calcium entry and endogenous dopamine release. Brain Res 368:174-177.

Lewis MJ (1991) Alcohol effects on brain-stimulation reward: blood alcohol concentration and site specificity. In: The neuropharmacology of ethanol. Boston: Birkhäuser.

Lochry EA, Riley E P (1980) Retention of passive avoidance and t-maze escape in rats exposed to alcohol prenatally. Neurobehav Toxicol 2:107-115.

McBride WJ, Guan X-M, Chernet E, Lumeng L, Li T-K (1990) Regional differences in the densities of serotonin-1A receptors between $\mathrm{P}$ and $\mathrm{NP}$ rats. Alcohol Clin Exp Res 14:316.

McBride WJ, Guan X-M, Chernet E, Lumeng L, Li T-K (1994) Regional serotonin $_{1 \mathrm{~A}}$ receptors in the CNS of alcohol-preferring and -nonpreferring rats. Pharmacol Biochem Behav 49:7-12.

McBride WT, Murphy JM, Lumeng L, Li T-K (1990) Serotonin, dopamine, and GABA involvements in alcohol drinking. Alcohol 7:199-203.

McBride WJ, Murphy JM, Gatto GJ, Levy AD, Lumeng L, Li T-K (1991) Serotonin and dopamine systems regulating alcohol intake. Alcohol Alcohol Suppl 1:411-416.

Meisch RA, Stewart RB (1994) Ethanol as a reinforcer: a review of laboratory studies of nonhuman primates. Behav Pharmacol 5:425-440.

Mena MA, Herrera E (1980) Monoamine metabolism in rat brain regions following long-term alcohol treatment. $\mathbf{J}$ Neural Transm 47:227-236.

Merlo Pich E, Lorang MT, Yeganeh M, De Fonseca FR, Raber J, Koob GF, Weiss F (1995) Increase of extracellular corticotropin-releasing factor levels in the amygdala of awake rats during restraint stress and ethanol withdrawal as measured by microdialysis. J Neurosci 15:5439-5447.

Mihic SJ, Harris RA (1995) $\Lambda$ lcohol actions at the GAB $\Lambda_{\mathrm{A}}$ receptor/ chloride channel complex. In: Alcohol and alcoholism. New York: Oxford UP, in press.

Miliaressis E, Bouchard A, Jacobowitz DM (1975) Strong positive reward in median raphe: specific inhibition by. Brain Res 98:194-201.

Monti JM, Alterwain P (1991) Ritanserin decreases alcohol intake in chronic alcoholics. Lancet 337:60.

Moolten M, Kornetsky C (1990) Oral self-administration of ethanol and not experimenter-administered ethanol facilitates rewarding electrical brain stimulation. Alcohol 7:221-225.

Morinan A (1987) Reduction in striatal 5-hydroxytryptamine turnover following chronic administration of ethanol to rats. Alcohol 22:53-60.

Murphy JM, McBride WJ, Lumeng L, Li TK (1982) Regional brain levels of monoamines in alcohol-preferring and non-preferring lines of rats. Pharmacol Biochem Behav 16:145-149.

Murphy JM, McBride WJ, Lumeng L, Li T-K (1987) Contents of monoamines in forebrain regions of alcohol-preferring (P) and nonpreferring (NP) lines of rats. Pharmacol Biochem Behav 26:389-392.

Murphy JM, McBride WJ, Gatto GJ, Lumeng L, Li T-K (1988) Effects of acute ethanol administration on monoamine and metabolite content in forebrain regions of ethanol-tolerant and -nontolerant alcoholpreferring $(P)$ rats. Pharmacol Biochem Behav 29:169-174.

Naranjo CA, Sellers EM, Roach CA, Woodley DV, Sanchez-Craig M, Sykora K (1984) Zimelidine-induced variations in alcohol intake by nondepressed heavy drinkers. Clin Pharmacol Ther 35:374-381.

Naranjo CA, Sellers EM, Sullivan JT, Woodley DV, Kadlec K, Sykora K (1987) The serotonin inhibitor citalopram attenuates ethanol intake. Clin Pharmacol Ther 41:266-274.

Naranjo C, Sullivan J, Kadlec K, Woodley-Remus D, Kennedy R, Sellers EM (1989) Differential effects of viqualine on alcohol intake and other consummatory behaviors. Clin Pharmacol Ther 46:301-309.

Naranjo C, Kadlec K, Sanhueza P, Woodley-Remus D, Sellers EM (1990) Fluoxetine differentially alters alcohol intake and other consummatory behaviors in problem drinkers. Clin Pharmacol Ther 47:490-498.

Nelson CR, Stussman BJ (1994) Alcohol- and drug-related visits to hos pital emergency departments: 1992 national hospital ambulatory medical care survey. Advance Data 10:1-6.

Parsons LH, Justice Jr JB (1992) Extracellular concentration and in vivo recovery of DA in the nucleus accumbens using microdialysis. J Neurochem 58:212-218.
Parsons LH, Justice JR (1993) Perfusate serotonin increases extracellular dopamine in the nucleus accumbens as measured by in vivo micro dialysis. Brain Res 606:195-199.

Patel VA, Pohorecky LA (1989) Acute and chronic ethanol treatment on beta-endorphin and catecholamine levels. Alcohol 6:59-63.

Paxinos G, Watson C (1986) The rat brain in sterotaxic coordinates. San Diego: Academic

Rassnick S, Koob GF, Geyer MA (1992) Responding to acoustic startle during chronic ethanol intoxication and withdrawal. Psychopharmacology 106:351-358.

Rassnick N, Pulvirenti L, Koob GF (1993) SDZ-205,152, a novel dopamine receptor agonist, reduces oral ethanol self-administration in rats. Alcohol 10:127-132.

Redgrave P, Horrell RI (1976) Potentiation of central reward by localised perfusion of acetylcholine and 5-hydroxytryptamine. Nature 262:305-307

Rice ME, Harris GT (1995) Psychopathy, schizophrenia, alcohol abuse, and violent recidivism. Int J Law Psychiatry 18:333-342.

Rossetti ZL, Melis F, Carboni S, Diana M, Gessa GL (1992) Alcohol withdrawal in rats is associated with a marked fall in extraneuronal dopamine. Alcohol Clin Exp Rcs 529-532.

Samson HS (1986) Initiation of ethanol reinforcement using a sucrosesubstitution procedure in food- and water-sated rats. Alcohol Clin Exp Res 10:436-442.

Samson HH (1992) The function of brain dopamine in ethanol reinforcement. In: Alcohol and neurobiology: receptors, membranes, and channels, pp 91-107. Boca Raton, FL: CRC.

Samson HH, Tolliver GA, Haraguchi M, Kalivas PW (1991) Effects of $d$-amphetamine injected into the $n$. accumbens on ethanol reinforced behavior. Brain Res Bull 27:267-271.

Schulteis G, Markou A, Cole M, Koob GF (1995) Decreased brain reward produced by ethanol withdrawal. Proc Natl Acad Sci USA 92:5880-5884.

Schulteis G, Hyytiä P, Heinrichs SC, Koob GF (1996) Effects of chronic ethanol exposure on oral self-administration of ethanol or saccharin by Wistar rats. Alcohol Clin Exp Res 20:164-171.

Sellers EM, Higgins GA, Sobel MB (1992) 5-HT and alcohol abuse. Trends Pharmacol Sci 13:69-75.

Signs SA, Schechter MD (1988) The role of dopamine and serotonin receptors in the mediation of the ethanol interoceptive cue. Pharmacol Biochem Behav 30:55-64.

Stewart RB, Gatto GJ, Lumeng L, Li T-K, Murphy JM (1993) Comparison of alcohol-preferring $(\mathrm{P})$ and nonpreferring (NP) rats on test of anxiety and for the anxiolytic effects of ethanol. Alcohol 10:1-10.

Tabakoff B, Hoffman P, Moses F (1977) Neurochemical correlates of cthanol withdrawal: alterations in serotoncrgic function. J Pharm Pharmacol 29:471-476.

Tabakoff B, Hoffman PL (1978) Alterations in receptors controlling dopamine synthesis after chronic ethanol ingestion. J Neurochem 31:1223-1229.

Tabakoff B, Hoffman PL (1996) Effects of aicohol on neurotransmitters and their receptors and enzymes. In: Alcohol and alcoholism pp. New York: Oxford UP, in press.

Tytell M, Myers RD (1973) Metabolism of $\left[{ }^{14} \mathrm{C}\right]$-serotonin in the caudate nucleus, hypothalamus and reticular formation of the rat after ethanol administration. Biochem Pharmacol 22:361-372.

Wahlström G, Magnusson O, Nordberg A, Stenström A, Tiger G (1991) Temporal studies of the inhibition of voluntary ethanol intake in the rat induced by intermittent ethanol treatment and some long term neurochemical consequences. Drug Alcohol Depend 28:129-144.

Waller MB, Murphy IM, McBride L, Lumeng I, Li T-K (1986) Effect of low-dose ethanol on spontaneous motor activity in alcohol-preferring and nonpreferring rats. Pharmacol Biochem Behav 24:617-623.

Weiss F, Koob GF (1991) The neuropharmacology of ethanol selfadministration. In: Neuropharmacology of ethanol: new approaches (Meyer RE, Koob GF, Lewis MJ, Paul SM, eds), pp 125-162. Boston: Birkhäuser.

Wciss F, Mitchincr M, Bloom FE, Koob GF (1990) Frec-choicc responding for ethanol versus water in alcohol-preferring $(\mathrm{P})$ and unselected Wistar rats is differentially altered by naloxone, bromocriptine and methysergide. Psychopharmacology 101:178-186.

Weiss F, Lorang MT, Bloom FE, Koob GF (1993) Oral alcohol selfadministration stimulates dopamine release in the rat nucleus accum- 
bens: genetic and motivational determinants. J Pharmacol Exp Ther 267:250-258.

Wozniak KM, Pert A, Mele A, Linnoila M (1991) Focal application of alcohols elevates extracellular dopamine in rat brain: a microdialysis study. Brain Res 540:31-40.

Yamamura T, Hishida S, Hatake K, Taniguchi T, Ouchi H (1992) Effects of methamphetamine and ethanol on learning and brain neurotransmitters in rats. Pharmacol Biochem Behav 42:389-400.

Yoshimoto K, Komura S (1987) Re-examination of the relationship between alcohol preference and brain monoamines in inbred strains of mice including senescence-accelerated mice. Pharmacol Biochem Behav 27:317-322.
Yoshimoto K, McBride WJ (1992) Regulation of nucleus accumbens dopamine release by the dorsal raphe nucleus in the rat. Neurochem Res 17:401-407.

Yoshimoto K, Komura S, Mizohata K (1985) Alcohol preference and brain monoamines in five inbred strains. IRCS Med Sci 13:1192-1193.

Yoshimoto K, McBride WJ, Lumeng L, Li T-K (1991) Alcohol stimulates the release of dopamine and serotonin in the nucleus accumbens. Alcohol 9:17-22.

Yoshimoto K, McBride WJ, Lumeng L, Li T-K (1992) Ethanol enhances the release of dopamine and serotonin in the nucleus accumbens of HAD and LAD lines of rats. Alcohol Clin Exp Res 16:781-785. 